Article

\title{
The Impaired Function of Macrophages Induced by Strenuous Exercise Could Not Be Ameliorated by BCAA Supplementation
}

\author{
Weihua Xiao *, Peijie Chen *, Xiaoguang Liu and Linlin Zhao \\ Received: 22 August 2015 ; Accepted: 14 October 2015 ; Published: 21 October 2015 \\ Department of Sports Science, Shanghai University of Sport, Shanghai 200438, China; \\ liuxiaoguang_sport@163.com (X.L.); linlinzhao666@163.com (L.Z.) \\ * Correspondence: xiaoweihua@sus.edu.cn (W.X.); chenpeijie@sus.edu.cn (P.C.); Tel.: +86-21-51253247
}

\begin{abstract}
The aim of this study was to evaluate the effect of strenuous exercise on the functions of peritoneal macrophages in rats and to test the hypothesis that branched-chain amino acid (BCAA) supplementation will be beneficial to the macrophages of rats from strenuous exercise. Forty male Wistar rats were randomly divided into five groups: (C) Control, E) Exercise, (E1) Exercise with one week to recover, (ES) Exercise + Supplementation and (ES1) Exercise + Supplementation with 1 week to recover. All rats except those of the sedentary control were subjected to four weeks of strenuous exercise. Blood hemoglobin, serum testosterone and BCAA levels were tested. Peritoneal macrophages functions were also determined at the same time. The data showed that hemoglobin, testosterone, BCAA levels, and body weight in group E decreased significantly as compared with that of group C. Meanwhile, phagocytosis capacity (decreased by $17.07 \%, p=0.031$ ), reactive oxygen species (ROS) production (decreased by $26 \%, p=0.003$ ) and MHC II mRNA (decreased by $22 \%$, $p=0.041$ ) of macrophages decreased in the strenuous exercise group as compared with group C. However, the chemotaxis of macrophages did not change significantly. In addition, BCAA supplementation could slightly increase the serum BCAA levels of rats from strenuous exercise (increased by $6.70 \%, p>0.05$ ). Moreover, the body weight, the blood hemoglobin, the serum testosterone and the function of peritoneal macrophages in group ES did not change significantly as compared with group E. These results suggest that long-term intensive exercise impairs the function of macrophages, which is essential for microbicidal capability. This may represent a novel mechanism of immunosuppression induced by strenuous exercise. Moreover, the impaired function of macrophage induced by strenuous exercise could not be ameliorated by BCAA supplementation in the dosing and timing used for this study.
\end{abstract}

Keywords: strenuous exercise; branched-chain amino acid; macrophages; function

\section{Introduction}

Exercise enhances or reduces immune functions depending on its frequency, duration and intensity. Regular physical activity is known to enhance immune functions leading to a decrease in the occurrence of infections. On the other hand, heavy or exhaustive exercise increases the susceptibility to infections [1-3]. Exercise increases or decreases the occurrence of infections that may be related to the changes of macrophage functions [4,5]. Monocytes/macrophages are considered to be the frontline of immunological defense against pathogens. These cells have prominent roles such as $\mathrm{Ag}$ presentation, chemotaxis, phagocytic, microbicidal, tumoricidal and secretory functions, as well as, innate immunity, by initiating inflammatory and immune responses [6]. Although some studies focus on the relationship between exercise and macrophages, little attention has been paid to the effects of long-term intensive exercise on macrophage functions. 
Branched-chain amino acid (BCAA) participates in skeletal muscle protein synthesis and can be used as energy substrates during physical exercise [7,8]. Therefore, since the 1980s, there has been high interest in BCAA by sports nutrition scientists. And now BCAA has been commonly used by Chinese athletes as nutritional supplements. What benefits can we get from the BCAA supplementation? Studies have shown that BCAA supplementation before and after exercise has beneficial effects for decreasing exercise-induced muscle damage and promoting muscle-protein synthesis $[9,10]$. However, many researchers have not been able to confirm that BCAA supplementation can enhance sports performance [11]. BCAAs act as donors of nitrogen and carbon skeleton for the synthesis of other amino acids, e.g., glutamine that are important in supporting immune cell function $[12,13]$. Thus, in recent years investigators have changed their research target and focused on the effects of BCAA on immune system. Cell culture and animal feeding studies indicate that an adequate supply of BCAA is necessary to support efficient immune function $[14,15]$. Conversely, insufficient availability of BCAA impairs some aspects of immune function, including killer-cell activity and lymphocyte proliferation $[14,15]$. However, many aspects of BCAAs and their effect on immune function have received little or no attention. For instance, we still do not know the effect of BCAA supplementation on the macrophage functions of rats from strenuous exercise.

Consequently, the aim of this study is to evaluate the effect of strenuous exercise on the functions of peritoneal macrophages in rats, and to test the hypothesis that BCAA supplementation will be beneficial to the macrophages of rats from strenuous exercise.

\section{Materials and Methods}

\subsection{Animals}

Forty male Wistar rats (mean weight $207 \pm 10.6 \mathrm{~g}$ ) were purchased from Shanghai SLAC laboratory animal center and were fed for one week acclimatization phase (environmental temperature $20-25{ }^{\circ} \mathrm{C}$ with a $12 \mathrm{~h}$ light/dark cycle and free access to standard pellets and drinking water). The rats were randomly divided into 5 groups $(n=8)$ : (C) Control, (E) Exercise, (E1) Exercise with 1 week to recover, (ES) Exercise + Supplementation and (ES1) Exercise + Supplementation with 1 week to recover. All groups except group $C$ were subjected to 4 weeks of strenuous exercise. In order to avoid the acute effect of exercise, the rats of group E and ES were killed at $36 \mathrm{~h}$ after the last training. The schematic representation of the experimental program is shown in Figure 1.

\subsection{Exercise Program}

The exercise program was based on a previously validated protocol [16]. All rats except those in group $C$ underwent daily running training sessions on a treadmill. The treadmill had different lanes to serve as corridors for each animal. In order to avoid the stimulation of the immune system, electric shock was not used in this study. We used our hands to ensure the animals ran effectively. The protocol included a 2-week progressive training program, starting with a 10-min running session at $6 \mathrm{~m} / \mathrm{min}$ and increasing gradually to steady-state $60-\mathrm{min}$ running at $36 \mathrm{~m} / \mathrm{min}$. Thereafter, animals were trained at this level 5 days a week for 4 weeks. At the same time, the sedentary control group was handled and exposed to the treadmill to control for stress of treadmill environment. The experimental protocol was approved by the Ethics Review Committee for Animal Experimentation of Shanghai University of Sports (Code number: 2014025).

\subsection{BCAA Supplementation}

The diet of rats was elaborated according to the recommendations of the American Institute of Nutrition (AIN-93M) for the maintenance of adult rodents (Research Diets, Inc., New Brunswick, USA) [17]. The composition of the experimental diets is shown in Table 1. Rats were fed with BCAA mixture ( $600 \mathrm{mg} / \mathrm{kg}$ body weight/day, consist of $46 \%$ leucine, $28 \%$ valine, and $23 \%$ isoleucine, Ajinomoto, Tokyo, Japan) (group ES and ES1) or saline (group C, E and E1) by gavage administration 
post-exercise and maintained for 4 weeks. The dose and delivery method of BCAA was determined based on previous studies [18,19].

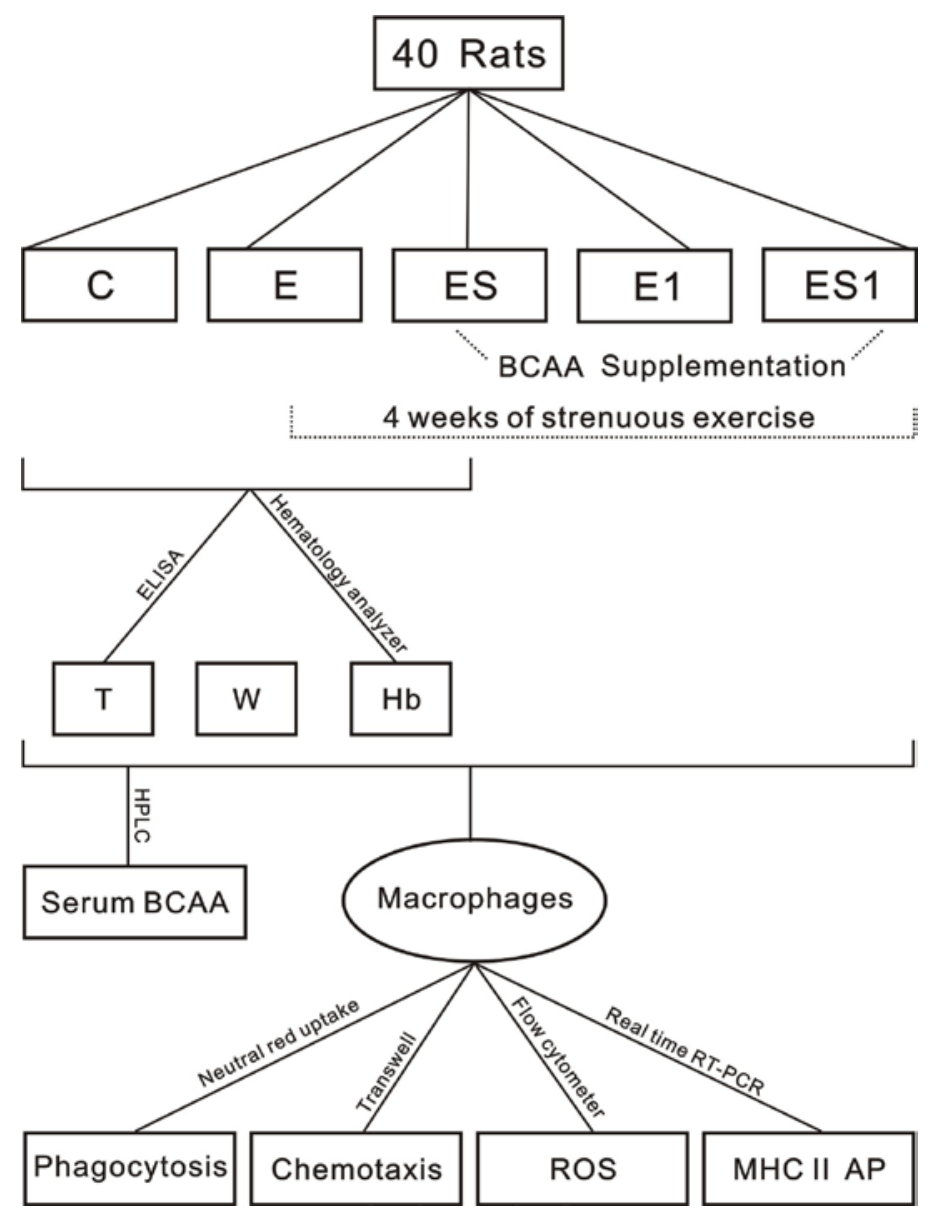

Figure 1. Schematic representation of the experimental program. Group C, Control; E, Exercise; E1, Exercise with 1 week to recover; ES, Exercise + Supplementation; ES1, Exercise + Supplementation with 1 week to recover. $\mathrm{T}$, testosterone; $\mathrm{W}$, weight; $\mathrm{Hb}$, hemoglobin; $\mathrm{BCAA}$, branched-chain amino acid; ROS, Reactive oxygen species; AP, antigen presentation.

Table 1. Composition of the experimental diets * $(\mathrm{g} / \mathrm{kg})$.

\begin{tabular}{ccc}
\hline Ingredients & g & kcal \\
\hline Casein & 140.000 & 560 \\
L-Cystine & 1.800 & 7.2 \\
Corn Starch & 495.692 & 1983 \\
Maltodextrin & 125 & 500 \\
Sucrose & 100.000 & 400 \\
Cellulose & 50.000 & 0 \\
Soybean Oil & 40.000 & 360 \\
$t$-Butylhydroquinone & 0.008 & 0 \\
Mineral mix & 35.000 & 0 \\
Vitamin mix & 10.000 & 40 \\
Choline bitartrate & 2.500 & 0 \\
Total & 1000 & 3850 \\
\hline
\end{tabular}

* The diet was elaborated according to the recommendations of the American; Institute of Nutrition (AIN-93M) for the maintenance of adult rodents [17]. 


\subsection{Biochemical Analyses}

Blood sample $(3 \mathrm{~mL})$ was taken from the fossa orbitalis venous plexus of rats. Blood hemoglobin, serum testosterone and serum BCAA level were determined. Blood hemoglobin was measured by hematology analyzer (Sysmex, Japan). Serum testosterone level was assessed using a commercial ELISA kit (AssayPro, St. Charles, MO, USA) according to the manufacturer's instructions. All samples and standards were measured in duplicate. BCAA levels in the serum were measured using high-performance liquid chromatography (HPLC, Hitachi, Ltd., Tokyo, Japan) according to the method by Deyl et al. [20].

\subsection{Peritoneal Macrophages Preparation}

As reported in our previous study [5], the MФs (peritoneal macrophages) were removed by peritoneal lavage using RPMI 1640 (GIBCO, Carlsbad, CA, USA). The cells were washed by centrifugation, resuspended in RPMI 1640 with $10 \%$ fetal bovine serum (GIBCO, Carlsbad, CA, USA), plus $1 \%$ penicillin-streptomycin solution, and then placed in 6-well tissue culture microplates. Plates were incubated for $2 \mathrm{~h}$ at $37^{\circ} \mathrm{C}$ in a humidified atmosphere of $5 \% \mathrm{CO}_{2}$. After the removal of non-adherent cells, the adherent cells were detached by treatment with $0.25 \%$ Trypsin and suspended in RPMI 1640 at a concentration of $2 \times 10^{6}$ cells $/ \mathrm{mL}$. Cell viability was checked with the Trypan blue dye and was $>96 \%$. Cell purity checked by the Giemsa dye test was $>98 \%$.

\subsection{Chemotaxis Assay}

Following Yang et al. [21] and Novak et al. [22], with little modification, the macrophages were washed twice in serum-free RPMI 1640 and resuspended at $1 \times 10^{6}$ cells $/ \mathrm{mL}$. $100 \mu \mathrm{L}$ cells were added into the upper chambers of a 24-well transwell plate with 8- $\mu \mathrm{m}$ pore size polycarbonate filters (Costar, Corning, NY, USA). The plate was equilibrated at $37^{\circ} \mathrm{C}$ in a $5 \% \mathrm{CO}_{2}$ cell culture incubator for $30 \mathrm{~min} .600 \mu \mathrm{L}$ of the serum-free RPMI 1640 (MCP-1, $10 \mathrm{ng} / \mathrm{mL}$, Sigma-Aldrich, St. Louis, MO, USA) was added into the lower chambers of the transwells to induce migration. After $2 \mathrm{~h}$ at $37^{\circ} \mathrm{C}$ in a $5 \% \mathrm{CO}_{2}$ cell culture incubator, the cells remaining in the upper chambers were wiped off with a cotton swab. Migrated cells attached to the lower surface of the filters were fixed with $75 \%$ ethanol for $30 \mathrm{~min}$, washed with water, and stained with hematoxylin. The number of migrated cells was counted under microscope. For each sample, cells in 5 randomly picked fields under $200 \times$ magnification were counted. Data were expressed relative to control group cell migration.

\subsection{Phagocytosis Assay}

The uptake of the neutral red by macrophages was measured following Long et al. [23] with the following modifications. The cell suspension $\left(2 \times 10^{6}\right.$ cells $\left./ \mathrm{mL}\right)$ was incubated in a 96-well flat-bottomed microtiter plate $100 \mu \mathrm{L} /$ well for $2 \mathrm{~h}$ at $37{ }^{\circ} \mathrm{C}$ in a $5 \% \mathrm{CO}_{2}$ cell incubator. After one wash with warm PBS (pH 7.2 to 7.4), $200 \mu \mathrm{L}$ of $0.1 \%$ neutral red (Amersco, Solon, OH, USA) solution in PBS was added. To minimize crystal formation during the neutral red assay, the dye solution was incubated overnight at $37^{\circ} \mathrm{C}$ and sterile filtered before use. After $30 \mathrm{~min}$ of incubation of the culture plates at $37^{\circ} \mathrm{C}$, neutral red solution was aspirated, and each well was thrice carefully rinsed with PBS. Finally, the intracellular dye was extracted with $200 \mu \mathrm{L}$ of a mixture of $100 \%$ ethanol and $99.9 \%$ acetic acid $(1: 1 \mathrm{v} / \mathrm{v})$. The mixtures were mixed fully and evaluated at a wavelength of $550 \mathrm{~nm}$ on a Bio-Rad 550 microplate reader (Bio-Rad Laboratories, Hercules, CA, USA). The absorbance represented phagocytosis by macrophages.

\subsection{Reactive Oxygen Species Determination}

Following Bae et al. [24], with little modification (no stimulus was added to the cell suspension to induce macrophage activation), the macrophages $\left(5 \times 10^{5}\right.$ cells) were incubated with $2^{\prime}, 7^{\prime}$-dichlorofluorescein diacetate (DCFH-DA; Molecular Probes) for $20 \mathrm{~min}$. The fluorescence 
intensity was analyzed by flow cytometry using a Coulter EPICS XL $\mathrm{L}^{\mathrm{TM}}$ flow cytometer with the System II ${ }^{\mathrm{TM}}$ software (Beckman Coulter, Fullerton, CA, USA). The level of ROS was expressed as relative fluorescence intensities generated by counting 10,000 cells.

\subsection{Real Time reverse-transcription polymerase chain reaction (Real Time RT-PCR)}

Total RNA of macrophages was isolated using a modified guanidinium isothiocyanate-CsCl method [25]. RNA was reverse transcribed into cDNA using the Revertaid ${ }^{\mathrm{TM}}$ First Strand cDNA Synthesis Kit from Fermentas. Quantitative PCR was carried out in triplicates in reactions consisting of $12.5 \mu \mathrm{L} 2 \times$ Maxima SYBR Green/ROX qPCR Master mix (Thermo Scientific), $1 \mu \mathrm{L}$ cDNA, nuclease-free water and $300 \mathrm{nM}$ of each primer [26]. Using Primer Express software (Applied Biosystems), we designed the following primers for the present study: $\beta$-actin (forword: $5^{\prime}$-GGA GAT TAC TGC CCT GGC TCC TA-3'; reverse: 5'-GAC TCA TCG TAC TCC TGC TTG CTG-3') and MHC II $\alpha$ chain (forword: 5'-AGA GAC CAT CTG GAG ACT TG-3'; reverse: 5'-CAT CTG GGG TGT TGT TGG A-3'). Amplifications were performed on a StepOne Plus ${ }^{\text {TM }}$ PCR-Cycler (Life Technologies) with the following parameters: activation at $95^{\circ} \mathrm{C}$ for $10 \mathrm{~min}, 40$ cycles of denaturation at $95{ }^{\circ} \mathrm{C}$ for $15 \mathrm{~s}$, and annealing/extension at $60^{\circ} \mathrm{C}$ for $1 \mathrm{~min}$. The threshold cycle $(\mathrm{CT}$, the number of cycles to reach threshold of detection) was determined for each reaction, and the levels of the target mRNAs were quantified relatively to the level of the housekeeping gene $\beta$-actin using $2^{-\Delta \Delta C T}$ method [27].

\subsection{Statistical Analysis}

All values are expressed as mean $\pm \mathrm{SD}$ ( Standard Deviation), and statistical significance was set at $p<0.05$. Mean values were compared between groups by ANOVA(Analysis of Variance) with the LSD(Least Significant Difference) method as a post hoc test. Data were analyzed using SPSS 19.0 for windows.

\section{Results}

\subsection{Body Weight, Hemoglobin and Testosterone Levels}

The mean final body weight and the mean concentrations of blood hemoglobin and serum testosterone are presented in Table 2. The weight of the rats of the strenuous exercise group was significantly lower than that of the sedentary control group (decreased by $13.86 \%, p=0.000$ ). In addition, blood assay showed that blood hemoglobin and serum testosterone in strenuous exercise group decreased significantly as compared with the sedentary control group (decreased by $9.27 \%$, $p=0.005 ; 31.40 \%, p=0.001$; respectively). Furthermore, body weight, blood hemoglobin and serum testosterone in group ES were still significantly lower than that of group $\mathrm{C}$. There was no significant difference between group ES and E ( $p>0.05)$.

Table 2. Body Weight, Hemoglobin and Testosterone levels.

\begin{tabular}{cccc}
\hline Group & Body Weight $(\mathrm{g})$ & Hemoglobin $(\mathrm{g} / \mathrm{L})$ & Testosterone $(\mathrm{ng} / \mathrm{mL})$ \\
\hline C & $318.25 \pm 11.57$ & $142.88 \pm 4.16$ & $4.49 \pm 0.55$ \\
E & $274.13 \pm 17.68^{* *}$ & $129.63 \pm 10.56^{* *}$ & $3.08 \pm 0.80^{* *}$ \\
ES & $277.75 \pm 14.48^{* *}$ & $132.87 \pm 9.50 *$ & $2.81 \pm 0.73^{* *}$ \\
\hline
\end{tabular}

Values are means \pm Standard Deviation (SD); ${ }^{*} p<0.05,{ }^{* *} p<0.01$ from control group. C, Control; E, Exercise; ES, Exercise + Supplementation.

\subsection{Serum BCAA Levels}

Figure 2 shows changes in serum BCAA levels after strenuous exercise and BCAA supplementation. The data showed that serum BCAA levels of rats from strenuous exercise group decreased significantly as compared with the rats from the sedentary group (decreased by $11.71 \%$, 
$p=0.007)$. On the other hand, BCAA supplementation could recover serum BCAA levels. There was no significant difference between group ES and C. After seven days of recovery, no difference was observed between group E1 and C.

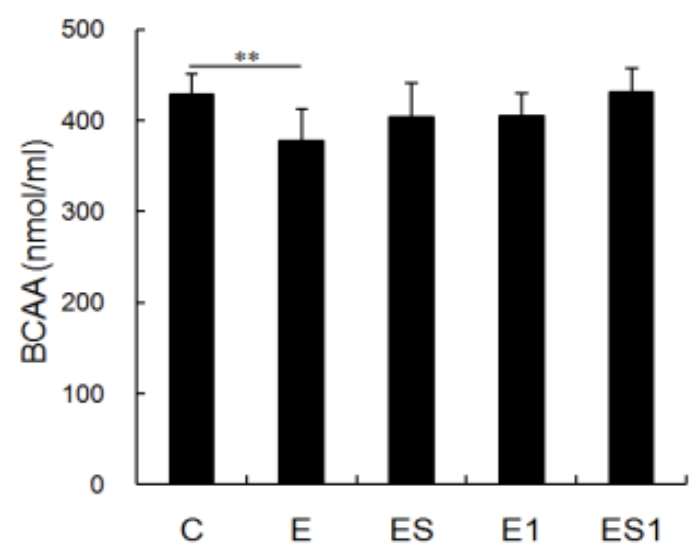

Figure 2. Effects of strenuous exercise and branched-chain amino acid (BCAA) supplementation on the serum BCAA concentration. BCAA levels in the serum were measured using high-performance liquid chromatography (HPLC). Data are means \pm Standard Deviation (SD). ${ }^{* *} p<0.01$. (C) Control; (E) Exercise; (E1) Exercise with 1 week to recover; (ES) Exercise + Supplementation; ES1) Exercise + Supplementation with 1 week to recover; the following are same.

\subsection{Phagocytosis}

Figure 3 shows changes in phagocytosis of MФs after strenuous exercise and BCAA supplementation. A decreased capacity for uptake of the neutral red (A550 nm) was observed in $\mathrm{M} \Phi$ s from the strenuous exercise group as compared with the cells from the sedentary group (Control vs. strenuous exercise, $0.41 \pm 0.06$ vs. $0.34 \pm 0.06$; decreased by $17.07 \%, p=0.031$ ). Furthermore, BCAA supplementation could not improve the phagocytosis of MФs (Control vs. ES, $0.41 \pm 0.06$ vs. $0.33 \pm 0.07$; decreased by $19.51 \%, p=0.018$ ). Meanwhile, there was no significant difference in the phagocytosis of MФs between group ES1, E1 and C.

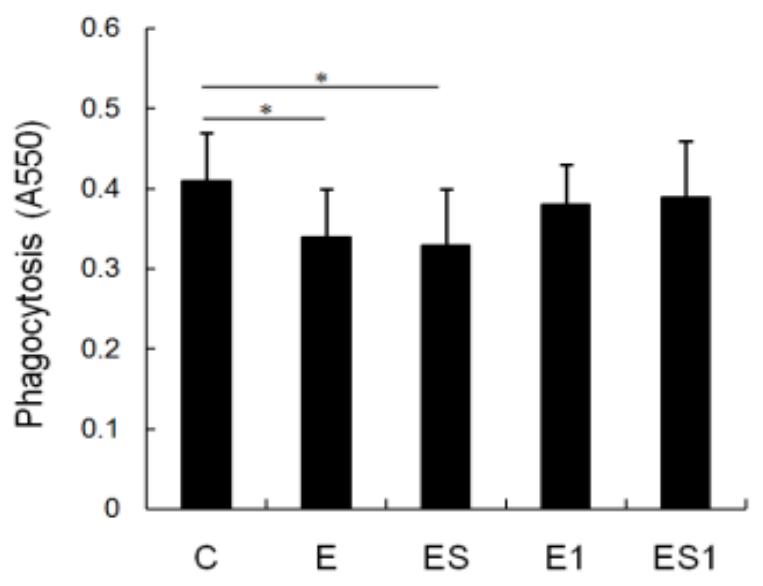

Figure 3. Effects of strenuous exercise and BCAA supplementation on the phagocytosis of MФs. MФs were incubated with $0.1 \%$ neutral red solution for $30 \mathrm{~min}$, as described in "Materials and Methods". The absorbance at a wavelength of $550 \mathrm{~nm}$ represented phagocytosis by macrophages. Data are means \pm SD of A550 nm. * $p<0.05$. 


\subsection{Chemotaxis}

Figure 4 shows changes in chemotaxis of $M \Phi s$ after strenuous exercise and BCAA supplementation. In this study, we added MCP-1 into the lower chambers of the transwells to induce migration. Data showed that the migration capacity of $M \Phi s$ from the strenuous exercise group has a tendency to increase as compared with the cells from the sedentary control. However, there was no significant difference between the two groups. Furthermore, BCAA supplementation could not change the chemotaxis of $\mathrm{M} \Phi$ s.

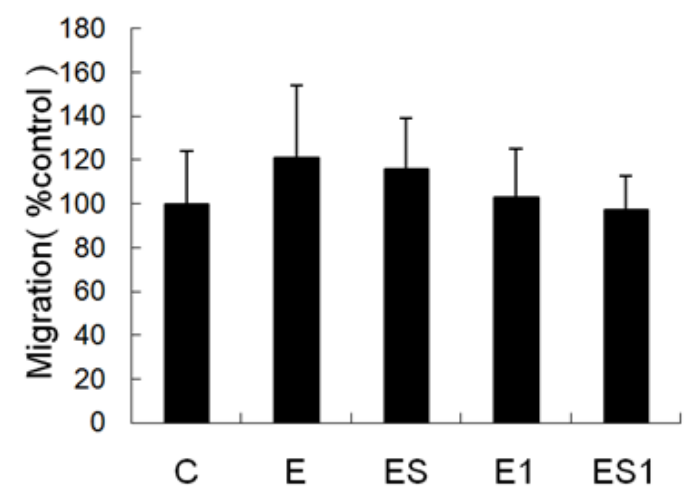

Figure 4. Effects of strenuous exercise and BCAA supplementation on the chemotaxis of MФs. MФs were added into the upper chambers of a 24-well transwell plate, while MCP-1 was added into the lower chambers of the transwells to induce migration. The number of migrated cells was counted. Data were expressed relative to control group cell migration. Data are means \pm SD.

\subsection{ROS Generation}

Figure 5 shows changes in ROS generation of MФs after strenuous exercise and BCAA supplementation. The production of ROS in MФs from the strenuous exercise group decreased significantly as compared with the cells from the sedentary group (Control vs. Strenuous exercise, $1.00 \pm 0.14$ vs. $0.74 \pm 0.16$; decreased by $26 \%, p=0.003$ ). After seven days of recovery, the ROS generation of MФs from group E1 was significantly higher than that of group $\mathrm{E}(p=0.000)$, and no difference was observed between group E1 and C. In addition, the ROS generation of MФs from group ES did not change as compared with group E. It was still significantly lower than that of group C $(p=0.020)$. Similarly, the ROS generation of MФs from group ES1 was significantly higher than that of group ES $(p=0.012)$, and there was no difference as compared with group E1 or C $(p>0.05)$.

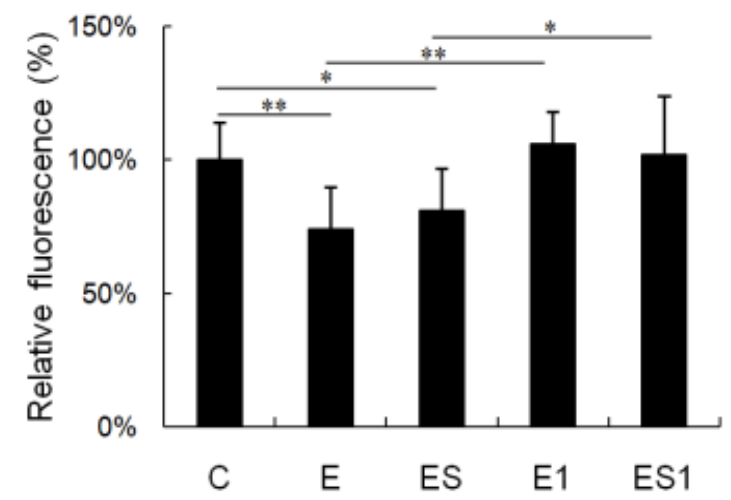

Figure 5. Effects of strenuous exercise and BCAA supplementation on the reactive oxygen species (ROS) generation of MФs. MФs were incubated with 2', $7^{\prime}$-dichlorofluorescein diacetate (DCFH-DA). DCFH-DA oxidation was monitored by flow cytometry. Data are means \pm SD of relative fluorescence intensity. ${ }^{*} p<0.05 ;{ }^{* *} p<0.01$. 


\subsection{MHC II mRNA Level}

Figure 6 shows changes in MHC II mRNA level of MФs after strenuous exercise and BCAA supplementation. Data showed that MHC II, the key molecule mediated macrophage antigen presentation [28-31], decreased significantly in the MФs of strenuous exercise rats (Control vs. Strenuous exercise, $1.00 \pm 0.19$ vs. $0.78 \pm 0.09$; decreased by $22 \%, p=0.041$ ). After seven days of recovery, MHC II mRNA of MФs from group E1 was significantly higher than group E ( $p=0.017)$, and no difference was observed between group E1 and C. In addition, MHC II mRNA of MФs from group ES did not change as compared with that of group E. It was still significantly lower than that of group C ( $p=0.047)$. Similarly, MHC II mRNA of MФs from group ES1 was significantly higher than that of group ES ( $p=0.003)$, and there was no difference as compared with group E1 or C $(p>0.05)$.

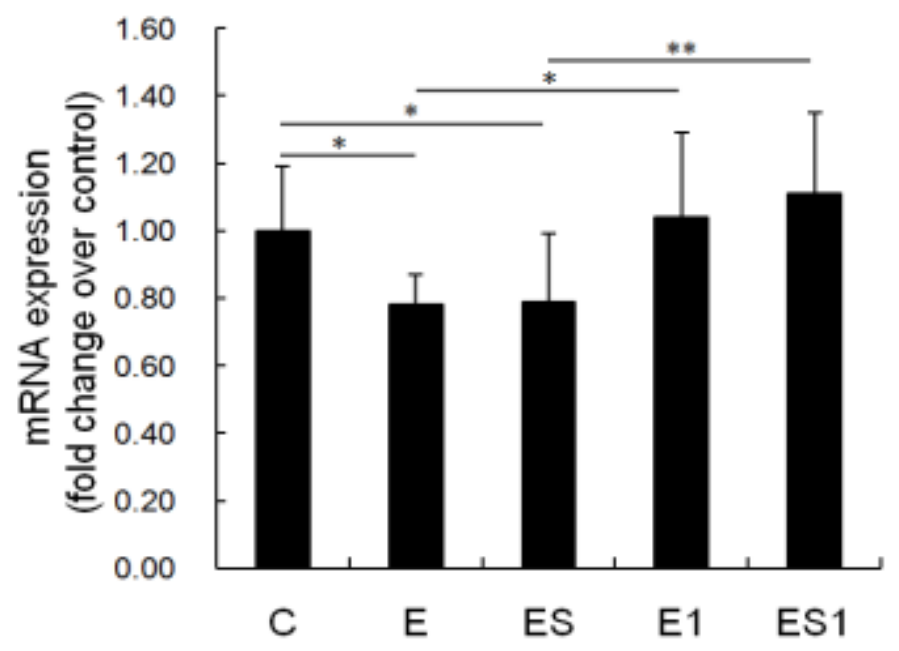

Figure 6. Effects of strenuous exercise and BCAA supplementation on MHC II mRNA level of MФs. Total RNA of macrophages was isolated and reverse transcribed into cDNA. Quantitative PCR was carried out using $\beta$-actin as the housekeeping gene. Data are means \pm SD. ${ }^{*} p<0.05$; ${ }^{* *} p<0.01$.

\section{Discussion}

In order to investigate the effects of strenuous exercise and BCAA supplementation on blood index of rats, blood hemoglobin and serum testosterone were tested. The data showed that blood hemoglobin and serum testosterone in the strenuous exercise group decreased significantly as compared with the control group. Furthermore, the body weight of the strenuous exercise group reduced significantly than that of the sedentary control. In addition, most of experimental groups could not keep up with the velocity of treadmill and had to be assisted by hand to complete the job at the last week of training. This means that the high-intensity exercise induced them to approach exhaustion. The data showed that the unbalanced condition was induced by four weeks of high-intensity training. Moreover, BCAA supplementation could not change the body weight, the blood hemoglobin and the serum testosterone as compared with group $\mathrm{E}$, which means that the unbalanced condition induced by strenuous exercise could not be improved by BCAA supplementation.

Phagocytosis, chemotaxis and antigen presentation are very important for macrophages in the removal of potentially pathogenic microorganisms [32]. Consequently, we tested the effects of strenuous exercise on the functions of $M \Phi s$. The results indicated that phagocytosis capacity (decreased by $17.07 \%, p<0.05)$ and major histocompatibility complex (MHC) II antigen (decreased by $22 \%, p<0.05$ ) of MФs from the strenuous exercise group was significantly lower than that of the control group. MHC II is a key molecule mediated macrophage antigen presentation [28-31]; meaning that MHC II mediated antigen presentation of MФs will be inhibited by strenuous exercise. 
Our results are similar to others. For instance, it has been reported that the phagocytosis of pulmonary alveolar macrophages (PAM) was impaired after seven weeks of strenuous exercise [33]. In the study of Woods et al., exhaustive exercise can negatively affect macrophages expression of MHC II, which may be detrimental to the ability of $M \Phi$ s to present antigen to T lymphocytes [34]. In addition, in a previous study we found that 11 weeks of overload training decreased the phagocytosis and chemotaxis of MФs [4]. However, in this study we did not find the decrease of chemotaxis of MФs after four weeks of strenuous exercise. The varying results may be influenced by the quality and/or quantity of exercise applied in the studies.

In addition, we measured the production of intracellular reactive oxygen species (ROS) in macrophages. To investigate the effect of strenuous exercise on the production of ROS, no stimulus (e.g., Lipopolysaccharides) was added to the cell suspension to induce macrophage activation. The data showed that the production of ROS in macrophages from strenuous exercise group was significantly lower than that of the control group (decreased by $26 \%, p<0.01$ ). The result is similar to our previous study, in which we found that ROS production of macrophages was inhibited by 11 weeks of overload training [4]. ROS are generally considered cytotoxic. However, intracellular ROS also serves as important second messengers in cell signaling [35]. A number of studies have shown that ROS play important roles in regulating macrophages' survival [36], differentiation [37] and secretion of inflammatory cytokines [38]. Therefore, the ROS level of macrophages from strenuous exercise group was lower than physiological levels, which would impair the function of macrophages mediated by ROS.

These results indicate that the functions (i.e., phagocytosis capacity, MHC II-mediated antigen presentation and ROS generation) of macrophages were inhibited by four weeks of high-intensity exercise, which could impair the removal capability of potentially pathogenic microorganisms. This may be a mechanism that explains why long-term intensive exercise induces immunodepression and increases the susceptibility to infections. Although the functions of macrophages were impaired after strenuous exercise, these functions were nearly recovered after one week recovery. It means that the hindering functions of macrophages induced by strenuous exercise, was non-permanent and reversible.

Taking account of the good effect of BCAA supplementation on immune system $[11,14,15]$, we speculated that BCAA supplementation would be beneficial to the macrophages of rats from strenuous exercise. The data showed that the phagocytosis, the ROS production and the MHC II mRNA of MФs from group ES was still significantly lower than that of group C. Moreover, there was no significant difference between that of groups ES and E. It means that the hindering function of MФs induced by strenuous exercise could not be ameliorated by BCAA supplementation. The results may be explained by the serum BCAA levels. In this study, we found that serum BCAA level decreased significantly in the rats of strenuous exercise. BCAA supplementation could slightly increase the serum BCAA level of rats from strenuous exercise; however, there was no significant difference between groups ES and E (increased by $6.70 \%, p>0.05$ ). Few studies have evaluated the roles of BCAA on macrophage function. For instance, Petro and Bhattacharjee reported that the ability of peritoneal macrophages to phagocytose and to kill S. typhimurium was not affected by BCAA restriction [39]. Kitagawa et al. also reported that BCAAs have protective effects on hepatic ischemia-reperfusion-induced liver injury through the attenuation of Kupffer cell (macrophage) activation [40]. In vitro experiments showed that high-BCAA medium increased IL-10 expression and phagocytic activity of microglial cells (macrophages) but did not affect the migration ability of these cells [41]. In spite of all these, our results are still difficult to compare with that of other studies owing to the fact that little attention has been paid to the effects of BCAA supplementation on peritoneal macrophage functions, especially in the model of strenuous exercise. If the data from rats are similar to human beings, then our results suggest that dietary BCAA supplementation is not useful to improving the macrophages function of people who engage in strenuous exercise. However, the effects of BCAA supplementation may be affected by many factors such as the dosing and timing. 
It is currently unknown whether the observed results could be affected by BCAA supplementation in the pre-workout period or at different doses.

\section{Conclusions}

Strenuous exercise impaired phagocytosis capacity, MHC II-mediated antigen presentation and ROS generation of macrophages. This may be a mechanism that explains why strenuous exercise induces immunodepression and increases the susceptibility to infections. Moreover, the impaired function of macrophage induced by strenuous exercise could not be ameliorated by BCAA supplementation in the dosing and timing used for this study.

Acknowledgments: This work was supported by the grants from National Natural Science Foundation of China (31271273, 31300975), the Doctoral Fund of Ministry of Education of China (20133156120004) and the Key Lab of Exercise and Health Sciences of Ministry of Education (Shanghai University of Sport).

Author Contributions: The authors' contributions are as follows: Weihua Xiao and Peijie Chen conducted the research and drafted the manuscript. Xiaoguang Liu and Linlin Zhao helped to collect the data. All authors read and approved the final manuscript.

Conflicts of Interest: The authors declared no conflict of interest.

\section{References}

1. Nieman, D.C. Clinical implications of exercise immunology. J. Sport Health Sci. 2012, 1, 12-17. [CrossRef]

2. Peijie, C.; Hongwu, L.; Fengpeng, X.; Jie, R.; Jie, Z. Heavy load exercise induced dysfunction of immunity and neuroendocrine responses in rats. Life Sci. 2003, 72, 2255-2262. [CrossRef]

3. Rama, L.; Teixeira, A.M.; Matos, A.; Borges, G.; Henriques, A.; Gleeson, M.; Pedreiro, S.; Filaire, E.; Alves, F.; Paiva, A. Changes in natural killer cell subpopulations over a winter training season in elite swimmers. Eur. J. Appl. Physiol. 2013, 113, 859-868. [CrossRef] [PubMed]

4. Xiao, W.H.; Chen, P.J.; Dong, J.M.; Wang, R.; Luo, B.B. Dietary glutamine supplementation partly reverses impaired macrophage function resulting from overload training in rats. Int. J. Sport Nutr. Exerc. Metab. 2015, 25, 179-187. [CrossRef] [PubMed]

5. Xiao, W.H.; Chen, P.J.; Wang, R.; Dong, J.M. Overload training inhibits phagocytosis and ROS generation of peritoneal macrophages: Role of IGF-1 and MGF. Eur. J. Appl. Physiol. 2013, 113, 117-125. [CrossRef] [PubMed]

6. Fujiwara, N.; Kobayashi, K. Macrophages in inflammation. Curr. Drug Targets Inflamm. Allergy 2005, 4, 281-286. [CrossRef] [PubMed]

7. Struder, H.K.; Hollmann, W.; Platen, P.; Wostmann, R.; Ferrauti, A.; Weber, K. Effect of exercise intensity on free tryptophan to branched-chain amino acids ratio and plasma prolactin during endurance exercise. Can. J. Appl. Physiol. Rev. Can. Physiol. Appl. 1997, 22, 280-291. [CrossRef]

8. Holecek, M.; Kandar, R.; Sispera, L.; Kovarik, M. Acute hyperammonemia activates branched-chain amino acid catabolism and decreases their extracellular concentrations: Different sensitivity of red and white muscle. Amino Acids 2011, 40, 575-584. [CrossRef] [PubMed]

9. Coombes, J.S.; McNaughton, L.R. Effects of branched-chain amino acid supplementation on serum creatine kinase and lactate dehydrogenase after prolonged exercise. J. Sports Med. Phys. Fit. 2000, 40, 240-246.

10. Shimomura, Y.; Yamamoto, Y.; Bajotto, G.; Sato, J.; Murakami, T.; Shimomura, N.; Kobayashi, H.; Mawatari, K. Nutraceutical effects of branched-chain amino acids on skeletal muscle. J. Nutr. 2006, 136, 529S-532S. [PubMed]

11. Negro, M.; Giardina, S.; Marzani, B.; Marzatico, F. Branched-chain amino acid supplementation does not enhance athletic performance but affects muscle recovery and the immune system. J. Sports Med. Phys. Fit. 2008, 48, 347-351.

12. Calder, P.C.; Yaqoob, P. Glutamine and the immune system. Amino Acids 1999, 17, 227-241. [CrossRef] [PubMed]

13. Newsholme, P. Why is L-glutamine metabolism important to cells of the immune system in health, postinjury, surgery or infection? J. Nutr. 2001, 131, 2515S-2522S. [PubMed]

14. Calder, P.C. Branched-chain amino acids and immunity. J. Nutr. 2006, 136, 288S-293S. [PubMed] 
15. Li, P.; Yin, Y.L.; Li, D.; Kim, S.W.; Wu, G. Amino acids and immune function. Br. J. Nutr. 2007, 98, $237-252$. [CrossRef] [PubMed]

16. Benito, B.; Gay-Jordi, G.; Serrano-Mollar, A.; Guasch, E.; Shi, Y.; Tardif, J.C.; Brugada, J.; Nattel, S.; Mont, L. Cardiac arrhythmogenic remodeling in a rat model of long-term intensive exercise training. Circulation 2011, 123, 13-22. [CrossRef] [PubMed]

17. Falavigna, G.; Alves de Araujo, J., Jr.; Rogero, M.M.; Pires, I.S.; Pedrosa, R.G.; Martins, E., Jr.; Alves de Castro, I.; Tirapegui, J. Effects of diets supplemented with branched-chain amino acids on the performance and fatigue mechanisms of rats submitted to prolonged physical exercise. Nutrients 2012, 4, 1767-1780. [CrossRef] [PubMed]

18. Iwasa, M.; Kobayashi, Y.; Mifuji-Moroka, R.; Hara, N.; Miyachi, H.; Sugimoto, R.; Tanaka, H.; Fujita, N.; Gabazza, E.C.; Takei, Y. Branched-chain amino acid supplementation reduces oxidative stress and prolongs survival in rats with advanced liver cirrhosis. PLoS ONE 2013, 8, e70309. [CrossRef] [PubMed]

19. Yamamoto, D.; Maki, T.; Herningtyas, E.H.; Ikeshita, N.; Shibahara, H.; Sugiyama, Y.; Nakanishi, S.; Iida, K.; Iguchi, G.; Takahashi, Y.; et al. Branched-chain amino acids protect against dexamethasone-induced soleus muscle atrophy in rats. Muscle Nerve 2010, 41, 819-827. [CrossRef] [PubMed]

20. Deyl, Z.; Hyanek, J.; Horakova, M. Profiling of amino acids in body fluids and tissues by means of liquid chromatography. J. Chromatogr. 1986, 379, 177-250. [CrossRef]

21. Yang, L.V.; Radu, C.G.; Wang, L.; Riedinger, M.; Witte, O.N. Gi-independent macrophage chemotaxis to lysophosphatidylcholine via the immunoregulatory GPCR G2A. Blood 2005, 105, 1127-1134. [CrossRef] [PubMed]

22. Novak, M.L.; Bryer, S.C.; Cheng, M.; Nguyen, M.H.; Conley, K.L.; Cunningham, A.K.; Xue, B.; Sisson, T.H.; You, J.S.; Hornberger, T.A.; et al. Macrophage-specific expression of urokinase-type plasminogen activator promotes skeletal muscle regeneration. J. Immunol. 2011, 187, 1448-1457. [CrossRef] [PubMed]

23. Long, F.; Wang, Y.X.; Liu, L.; Zhou, J.; Cui, R.Y.; Jiang, C.L. Rapid nongenomic inhibitory effects of glucocorticoids on phagocytosis and superoxide anion production by macrophages. Steroids 2005, 70, 55-61. [CrossRef] [PubMed]

24. Bae, Y.S.; Lee, J.H.; Choi, S.H.; Kim, S.; Almazan, F.; Witztum, J.L.; Miller, Y.I. Macrophages generate reactive oxygen species in response to minimally oxidized low-density lipoprotein: Toll-like receptor 4- and spleen tyrosine kinase-dependent activation of nadph oxidase 2. Circ. Res. 2009, 104, 210-218. [CrossRef] [PubMed]

25. Chirgwin, J.M.; Przybyla, A.E.; MacDonald, R.J.; Rutter, W.J. Isolation of biologically active ribonucleic acid from sources enriched in ribonuclease. Biochemistry 1979, 18, 5294-5299. [CrossRef] [PubMed]

26. Xiao, W.; Chen, P.; Dong, J. Effects of overtraining on skeletal muscle growth and gene expression. Int. J. Sports Med. 2012, 33, 846-853. [CrossRef] [PubMed]

27. Livak, K.J.; Schmittgen, T.D. Analysis of relative gene expression data using real-time quantitative PCR and the 2- $\Delta \Delta C$ T method. Methods 2001, 25, 402-408. [CrossRef] [PubMed]

28. Chang, S.T.; Linderman, J.J.; Kirschner, D.E. Multiple mechanisms allow mycobacterium tuberculosis to continuously inhibit MHC class II-mediated antigen presentation by macrophages. Proc. Natl. Acad. Sci. USA 2005, 102, 4530-4535. [CrossRef] [PubMed]

29. Noss, E.H.; Pai, R.K.; Sellati, T.J.; Radolf, J.D.; Belisle, J.; Golenbock, D.T.; Boom, W.H.; Harding, C.V. Toll-like receptor 2-dependent inhibition of macrophage class II MHC expression and antigen processing by 19-KDA lipoprotein of mycobacterium tuberculosis. J. Immunol. 2001, 167, 910-918. [CrossRef] [PubMed]

30. Germain, R.N. MHC-dependent antigen processing and peptide presentation: Providing ligands for $\mathrm{T}$ lymphocyte activation. Cell 1994, 76, 287-299. [CrossRef]

31. Chu, R.S.; Askew, D.; Noss, E.H.; Tobian, A.; Krieg, A.M.; Harding, C.V. CPG oligodeoxynucleotides down-regulate macrophage class II MHC antigen processing. J. Immunol. 1999, 163, 1188-1194. [PubMed]

32. Taylor, A.E.; Finney-Hayward, T.K.; Quint, J.K.; Thomas, C.M.R.; Tudhope, S.J.; Wedzicha, J.A.; Barnes, P.J.; Donnelly, L.E. Defective macrophage phagocytosis of bacteria in copd. Eur. Respir. J. 2010, 35, 1039-1047. [CrossRef] [PubMed]

33. Raidal, S.L.; Love, D.N.; Bailey, G.D.; Rose, R.J. The effect of high intensity exercise on the functional capacity of equine pulmonary alveolar macrophages and BAL-derived lymphocytes. Res. Vet. Sci. 2000, 68, 249-253. [CrossRef] [PubMed] 
34. Woods, J.A.; Ceddia, M.A.; Kozak, C.; Wolters, B.W. Effects of exercise on the macrophage MHC II response to inflammation. Int. J. Sports Med. 1997, 18, 483-488. [CrossRef] [PubMed]

35. Rhee, S.G. Cell signaling. H2O2, a necessary evil for cell signaling. Science 2006, 312, 1882-1883. [CrossRef] [PubMed]

36. Wang, Y.; Zeigler, M.M.; Lam, G.K.; Hunter, M.G.; Eubank, T.D.; Khramtsov, V.V.; Tridandapani, S.; Sen, C.K.; Marsh, C.B. The role of the NADPH oxidase complex, p38 MAPK, and AKT in regulating human monocyte/macrophage survival. Am. J. Respir. Cell Mol. Biol. 2007, 36, 68-77. [CrossRef] [PubMed]

37. Lee, N.K.; Choi, Y.G.; Baik, J.Y.; Han, S.Y.; Jeong, D.W.; Bae, Y.S.; Kim, N.; Lee, S.Y. A crucial role for reactive oxygen species in RANKL-induced osteoclast differentiation. Blood 2005, 106, 852-859. [CrossRef] [PubMed]

38. Brown, D.M.; Donaldson, K.; Borm, P.J.; Schins, R.P.; Dehnhardt, M.; Gilmour, P.; Jimenez, L.A.; Stone, V. Calcium and ROS-mediated activation of transcription factors and TNF- $\alpha$ cytokine gene expression in macrophages exposed to ultrafine particles. Am. J. Physiol. Lung Cell. Mol. Physiol. 2004, 286, L344-L353. [CrossRef] [PubMed]

39. Petro, T.M.; Bhattacharjee, J.K. Effect of dietary essential amino acid limitations upon the susceptibility to Salmonella typhimurium and the effect upon humoral and cellular immune responses in mice. Infect. Immun. 1981, 32, 251-259. [PubMed]

40. Kitagawa, T.; Yokoyama, Y.; Kokuryo, T.; Nagino, M. Protective effects of branched-chain amino acids on hepatic ischemia-reperfusion-induced liver injury in rats: A direct attenuation of Kupffer cell activation. Am. J. Physiol. Gastrointest. Liver Physiol. 2013, 304, G346-G355. [CrossRef] [PubMed]

41. De Simone, R.; Vissicchio, F.; Mingarelli, C.; De Nuccio, C.; Visentin, S.; Ajmone-Cat, M.A.; Minghetti, L. Branched-chain amino acids influence the immune properties of microglial cells and their responsiveness to pro-inflammatory signals. Biochim. Biophys. Acta 2013, 1832, 650-659. [CrossRef] [PubMed]

(C) 2015 by the authors; licensee MDPI, Basel, Switzerland. This article is an open access article distributed under the terms and conditions of the Creative Commons by Attribution (CC-BY) license (http://creativecommons.org/licenses/by/4.0/). 